\title{
Increased Glutamate and Homocysteine and Decreased Glutamine Levels in Autism: A Review and Strategies for Future Studies of Amino Acids in Autism
}

\author{
Ahmad Ghanizadeh ${ }^{1,2}$ \\ ${ }^{1}$ Research Center for Psychiatry and Behavioral Sciences, Shiraz University of Medical Sciences, Shiraz, Iran \\ ${ }^{2}$ Department of Psychiatry, School of Medicine, Shiraz University of Medical Sciences, Shiraz, Iran \\ Correspondence should be addressed to Ahmad Ghanizadeh; ghanizadeha@hotmail.com
}

Received 11 June 2013; Accepted 12 August 2013

Academic Editor: Grant Izmirlian

Copyright (C) 2013 Ahmad Ghanizadeh. This is an open access article distributed under the Creative Commons Attribution License, which permits unrestricted use, distribution, and reproduction in any medium, provided the original work is properly cited.

There are many reports about the significant roles of some amino acids in neurobiology and treatment of autism. This is a critical review of amino acids levels in autism. No published review article about the level of amino acids in autism was found. The levels of glutamate and homocystein are increased in autism while the levels of glutamine and tryptophan are decreased. Findings regarding the plasma levels of taurine and lysine are controversial. The urinary levels of homocysteine and essential amino acids in both the untreated and treated autistic children are significantly less than those in the controls. The current literature suffers from many methodological shortcomings which needed to be considered in future studies. Some of them are age, gender, developmental level, autism symptoms severity, type of autism spectrum disorders, medical comorbidities, intelligent quotient, diet, concomitant medications, body mass index, and technical method of assessment of amino acids.

\section{Introduction}

Autism is one of the different subtypes of autism spectrum disorders. Its main characteristics are deficits in social communication and relationship, verbal communication and language impairments, and repetitive/restrictive behaviors and interests.

Many children with autism are picky eaters. They do not like a variety of different foods. Eating problems are risk factors for nutritional deficiencies. Some of these children do not like to try new foods and have food selectivity [1]. Food refusal and food selectivity are reported in $90 \%$ of these children [2]. Children with autism intake vitamin B6 and vitamin E more than the controls [3]. However, their take of vitamin $\mathrm{B} 12$ is less than that of the typical controls [4]. In addition, the level of vitamin B6 in plasma is very high in autism [5].

Moreover, there are contradictory reports about the level of intake of proteins by children with autism. For example, a study reported that the protein intake of children with autism is significantly less than the typical controls [4]. Meanwhile, others reported that daily protein intake of children with autism is higher than that of the controls $[3,6]$. Nevertheless, another study could not find a difference between autism and controls [7].

Children with autism suffer from deficiency of essential plasma amino acids displaying their poor protein intakes [8]. While the rate of at least one essential amino acid (valine, leucine, phenylalanine, and lysine) deficiency in autism was $58 \%$, the rate in the control group was 4\% [8]. Another study compared plasma level of 25 amino acids between high-functioning autism children and the healthy controls [9]. The study showed that only the levels of glutamate and glutamine were different between the two groups. While the level of glutamate was increased, the level of glutamine was decreased (Table 1) [9]. The levels of other amino acids were not different between high-functioning autism children and healthy controls [9]. The authors suggested that the plasma level of these two amino acids may differentiate high IQ autism and normal children. The deregulation of amino acids in autism was also reported in siblings and parents of these children [10].

Glutamate is involved in neuroinflammation in autism [11]. Moreover, targeting glutamate receptors through glycine 
TABLE 1: A summary of the studies regarding amino acids in children with autism.

\begin{tabular}{|c|c|c|}
\hline Study & Methodological issues & Main findings \\
\hline Shimmura et al. [9] & $\begin{array}{l}\text { Comparing the levels of } 25 \text { amino acids, including } \\
\text { glutamate and glutamine, in the platelet-poor plasma of } \\
\text { drug-naive, male children with high-functioning } \\
\text { autism (HFA) would be altered compared with those of } \\
\text { normal controls using high-performance liquid } \\
\text { chromatography }\end{array}$ & $\begin{array}{l}\text { Plasma glutamate: } \mathrm{HFA}^{*} \text { group > control, } \\
\text { plasma glutamine: control > HFA } \\
\text { Other } 23 \text { amino acids: no significant group } \\
\text { difference }\end{array}$ \\
\hline Moreno-Fuenmayor et al. [15] & $\begin{array}{l}\text { Plasma amino acid levels were measured by } \\
\text { high-pressure liquid chromatography (HPLC) in } 14 \\
\text { children with autism aged less than } 10 \text { years }\end{array}$ & $\begin{array}{l}\text { Glutamic: autism }>\text { normal values } \\
\text { Aspartic acid: autism }>\text { normal values } \\
\text { Taurine: autism }>\text { normal values } \\
\text { Glutamine: autism }<\text { normal values } \\
\text { Asparagine: autism }<\text { normal values }\end{array}$ \\
\hline Aldred et al. [10] & $\begin{array}{l}\text { Plasma amino acid levels were compared between } \\
\text { autistic and Asperger syndrome children and their } \\
\text { siblings, parents, and their aged matched controls }\end{array}$ & $\begin{array}{l}\text { Glutamic acid: autism }>\text { controls } \\
\text { Phenylalanine: autism }>\text { controls } \\
\text { Asparagine: autism }>\text { controls } \\
\text { Tyrosine: autism }>\text { controls } \\
\text { Alanine: autism }>\text { controls } \\
\text { Lysine: autism }>\text { controls } \\
\text { Glutamine: autism }<\text { controls }\end{array}$ \\
\hline Tu et al. [16] & $\begin{array}{l}\text { Plasma amino acids profiles of } 20 \text { children with autism } \\
\text { were compared with those of age and gender matched } \\
\text { group of children }\end{array}$ & $\begin{array}{l}\text { Lysine: autism > controls } \\
\text { Glutamic acid: autism }>\text { controls } \\
\text { Homocysteine: autism }>\text { controls } \\
\text { Leucine: autism }<\text { controls } \\
\text { Tryptophan: autism }<\text { controls } \\
\text { Valine: autism }<\text { controls } \\
\text { Taurine: autism }<\text { controls } \\
\text { Tyrosine: autism }<\text { controls } \\
\text { Glutamine: autism }<\text { controls }\end{array}$ \\
\hline Tirouvanziam et al. [17] & $\begin{array}{l}\text { Compared plasma amino acid levels in children with } \\
\text { Autism spectrum disorders (ASD, } N=27) \text { and } \\
\text { neurotypically developing controls }(N=20)\end{array}$ & $\begin{array}{l}\text { Glutamate: autism }>\text { controls } \\
\text { Glutamine: autism }<\text { controls } \\
\text { Threonine: autism }<\text { controls } \\
\text { Asparagine: autism }<\text { controls } \\
\text { Citrulline: autism }<\text { controls } \\
\text { Serine: autism }<\text { controls } \\
\text { Tyrosine: autism }<\text { controls } \\
\text { Leucine: autism }<\text { controls }\end{array}$ \\
\hline
\end{tabular}

${ }^{*}$ High functioning autism.

site on NMDA receptor is supposed as a target for treating autism [12]. In addition, methionine sulfoximine may improve inflammation in autism [13]. Besides, many children with autism suffer from irritability and aggression. The levels of homocysteine and glutamate are associated with each other, and this is supposed to be a target for treating aggression [14].

This is a narrative critical review of amino acids levels in autism. There is a positive correlation between cerebrospinal level of glutamate level and its plasma level [18]. Meanwhile, its level in serum is several times more than the CSF level. Therefore, the levels of amino acids in plasma, brain, and urine are reviewed. To the best of author's knowledge, no published review article about the levels of amino acids in autism has been published yet.

\section{Amino Acids Levels}

2.1. Glutamate. Glutamate is a major excitatory neurotransmitter in the brain. The high level of plasma glutamate level especially in children with normal IQ is supposed to be a diagnostic screening test [9]. The increased plasma level in adults with autism is also reported [19]. Higher glutamate level is not limited to plasma, and some studies confirmed its higher level in some brain regions (amygdala-hippocampal regions but not in parietal region) of patients with autism compared to the controls [20]. The increased plasma glutamic acid is not limited to patients with autism, but its level is increased in their siblings and parents [10]. Another study measured plasma amino acid levels in 14 young children with autism by high-pressure liquid chromatography (HPLC). The mean glutamic acid was increased [15].

2.2. Glutamine. The low level of plasma glutamine level is suggested as a screening test for detecting autism in children especially those with normal IQ [9]. The decreased level has been reported before in all children with autism $[10,15,16]$ (Table 2).

2.3. Taurine. Taurine is an inhibitory amino acid whose plasma level is increased in autism [15]. It is suggested that 
TABLE 2: The level of amino acids in patients with autism in comparison to healthy controls.

\begin{tabular}{|c|c|}
\hline Amino acid & Status \\
\hline Leucine & $\begin{array}{l}\text { Decreased in CSF }[21] \\
\text { Decreased in plasma }[8,16,17,21]\end{array}$ \\
\hline Lysine & $\begin{array}{l}\text { Increased in plasma }[8,10,16] \\
\text { No difference in plasma }[17]\end{array}$ \\
\hline Tryptophan & Decreased in plasma $[16,17]$ \\
\hline Taurine & $\begin{array}{l}\text { Decreased in plasma }[16] \\
\text { Increased in plasma }[15,22]\end{array}$ \\
\hline Homocysteine & $\begin{array}{l}\text { Increased in serum }[16,23] \\
\text { Increased total homocysteine (tHcy) in serum } \\
\text { [24] } \\
\text { Decreased plasma levels of homocysteine [25] } \\
\text { Increased level in urine [26] }\end{array}$ \\
\hline Citrulline & Decreased in plasma [17] \\
\hline Alanine & $\begin{array}{l}\text { No difference in plasma [17] } \\
\text { Increased in plasma [10] }\end{array}$ \\
\hline Glycine & No difference in plasma [17] \\
\hline Valine & $\begin{array}{l}\text { Decreased in plasma }[8,16] \\
\text { No difference in plasma }[17]\end{array}$ \\
\hline Aspartic acid & Decreased platelet levels [27] \\
\hline GABA & Decreased platelet levels [27] \\
\hline Arginine & No difference in plasma [17] \\
\hline Isoleucine & Decreased [21] \\
\hline Threonine & Decreased in plasma [17] \\
\hline Serine & Decreased in plasma [17] \\
\hline Proline & No difference in plasma [17] \\
\hline Asparagine & $\begin{array}{l}\text { Decreased in plasma }[15,17] \\
\text { Increased in plasma }[10]\end{array}$ \\
\hline Aspartic acid & No difference in plasma [17] \\
\hline Methionine & $\begin{array}{l}\text { Increased in plasma [8] } \\
\text { Decreased [21] }\end{array}$ \\
\hline Glycine & No difference in serum level [19] \\
\hline D-serine & No difference in serum level [19] \\
\hline L-serine & No difference in serum level [19] \\
\hline Glutamic acid & $\begin{array}{l}\text { Increased in plasma }[10,16,17] \\
\text { Decreased platelet levels }[27]\end{array}$ \\
\hline Glutamate & $\begin{array}{l}\text { Increased level in plasma }[9,10,15,19,28] \\
\text { Increased in some regions of brain }[20]\end{array}$ \\
\hline Aspartate & Increased in plasma [22] \\
\hline Phenylalanine & $\begin{array}{l}\text { Decreased in plasma }[8,17] \\
\text { Increased in plasma }[10]\end{array}$ \\
\hline Glutamine & $\begin{array}{l}\text { Decreased in plasma }[9,10,15-17] \\
\text { No difference in serum level [19] } \\
\text { Decreased platelet levels [27] }\end{array}$ \\
\hline Lysine & Increased in plasma [10] \\
\hline Tyrosine & $\begin{array}{l}\text { Decreased in plasma }[16,17] \\
\text { Increased in plasma }[10]\end{array}$ \\
\hline
\end{tabular}

its higher level is a compensatory phenomenon for the increased glutamate level [15]. Nevertheless, others reported that the mean level of taurine is decreased in autism [16].

2.4. Homocysteine. A study reported that the plasma levels of homocysteine were low in autism [25]. However, their subjects were taking supplements of folic acid and vitamin
B12 before being included in the study. These vitamins may be involved in reducing homocysteine level. Homocysteine is converted to methionine [29]. This process needs vitamin B12. Therefore, the deficiency of vitamin may increase the level of homocysteine. Meanwhile, other well-controlled study showed that the serum level of homocysteine is increased in autism $[16,23,24]$.

2.5. Other Amino Acids. There are many reports about the increased plasma level of lysine in autism $[8,10,16]$. Meanwhile, a study reported that lysine level in autism is not different with in the controls [17]. The level of aspartic acid is increased as well [16]. All of the studies reported that the level of tryptophan is decreased in autism $[16,17]$.

\section{Amino Acids Levels in Urine}

The level of homocysteine in overnight urine sample in autism is increased [26]. This reduction may be due to the deficiency of folic acid and vitamins B6 and B12.

In addition, the urinary levels of essential amino acids in both the untreated and treated autistic children are significantly less than those the controls [30]. The levels of alanine, a-Aminobutyric acid, valine, leucine, isoleucine, threonine, serine, proline, asparagine, aspartic acid, glutamic acid, phenylalanine, a-Aminoadipic acid, glutamine, glycineproline, lysine, histidine, tyrosine, proline-hydroxyproline, Tryptophan, and total essential amino acids in untreated autism in first urine of the morning are less than those of the controls [30].

\section{Discussion}

Current findings support that many children with autism suffer from amino acids metabolism impairment. Nearly, all the studies reported higher levels of plasma glutamate in autism than those of the controls. In addition, the lower level of glutamine is frequently reported. Hyperglutamatergic state causes excitotoxicity and neurodegeneration [31]. Glutamate easily passes through blood brain barrier [31]. It is suggested that hyperglutamatergic state is an etiology of autism [32]. This state is associated with exacerbation of inflammation in the brain [33]. Moreover, this increased glutamate level is compatible with the findings that the level of proteins involved in transforming glutamate to GABA is decreased [34]. A well-controlled study confirmed that the plasma glutamate level is increased while the level of glutamine is decreased in children with autism [9]. The increased serum level of glutamate in autism is weakly associated with severity of autism [19]. Another study also reported that there was a statistically nonsignificant increase of platelet-poor plasma glutamate in autism [17].

In summary, children with autism more likely have essential amino acids deficiency, and this may make them prone to a higher deficiency if they are under a specific diet.

4.1. Future Directions. There are many shortcomings in the current literature regarding the level of amino acids in autism. 
Many of the following methodological issues have never been considered in the current literature.

(1) Further studies should investigate whether the levels of different amino acids are associated with age and gender in autism. At least one study reported that the pattern of amino acids is associated with age while it is not associated with gender [17]. Although it is suggested that the increased level of glutamate is stable in later ages [9], it needs to examine whether the findings can be generalized to different ages. A study reported that some biomarkers are gender related in patients with Asperger's syndrome [35]. The rate of autism is gender dependent as well [36].

(2) Besides, it is not examined whether the profile of amino acids in autism is associated with the developmental level, autism symptoms severity, and psychiatric disorders comorbidities. The rate of psychiatric comorbidity is up to 74\% [37]. About half of children with autism meet diagnostic criteria for ADHD [38].

(3) Autism is one of the disorders in the spectrum of pervasive developmental disorders. Whether the pattern of amino acids is different between the different types of autism spectrum disorders needs to be clarified. Whether current findings can be generalized to all the types of autism needs to be investigated.

(4) In addition, many children with autism have some medical comorbidities such as Down's syndrome, Fragile X syndrome, epilepsy, and/or tuberous sclerosis. These comorbidities need to be considered as covariates in further studies.

(5) The intelligent quotient of about two-thirds of children with autism is less than 75 [39]. In other words, majority of children with autism suffer from mental retardation. Few studies considered IQ as a possible covariate [9].

(6) Moreover, future studies should examine the possible role of any diet regime or food habits as covariate factors. It should be clarified whether the possible profile of amino acids in autism is secondary to the food and diet pattern. Some instruments assess the diet or food pattern of children. However, these instruments are very different. For example, some of them may evaluate the food pattern during a few days while others may assess it during a few months.

(7) Gastrointestinal problems are not uncommon in children with autism. About one-fourth of them have at least one of the problems of constipation, abdominal pain, bloating, diarrhea, and/or nausea lasting three or more months [40]. Is there any role for these problems to impact amino acids levels in autism?

(8) Further studies should investigate why glutamate level is increased in autism. Is it due to dietary origin, metabolic problems, vitamin B6 involvement, glutamate receptor problems, and glutamate transporters problems or all of them?
(9) There is a speculation about the possible role of human gut microbiota in the etiology of autism [41]. Some of the microbial metabolites may affect brain function [42] through impacting aromatic amino acids metabolism [43].

(10) The ratio of the different amino acids is another item which needs to be considered in future studies. Because one study indicated that several amino acids, individually or combined, differentiate autism spectrum disorder and healthy controls [17].

(11) Past history of medication is another covariate. We do not know whether the changes are due to the effect of drugs. The levels of some amino acids in urine of treated children with autism are different from those of untreated ones [30].

(12) Body mass index and creatinine level may impact on amino acids levels.

(13) The technical method of assessment of amino acid should be considered to decrease the possibility of plasma contamination from other resources of amino acids such as platelets. Serum, platelet-poor plasma, and platelet-riched plasma should be differentiated. Further studies should consider 24-hour collection rather than spot collection.

\section{References}

[1] T. V. Kral, W. T. Eriksen, M. C. Souders, and J. A. Pinto-Martin, "Eating behaviors, diet quality, and gastrointestinal symptoms in children with autism spectrum disorders: a brief review," Journal of Pediatric Nursing, 2013.

[2] W. H. Ahearn, T. Castine, K. Nault, and G. Green, "An assessment of food acceptance in children with autism or pervasive developmental disorder-not otherwise specified," Journal of Autism and Developmental Disorders, vol. 31, no. 5, pp. 505-511, 2001.

[3] A. C. Herndon, C. DiGuiseppi, S. L. Johnson, J. Leiferman, and A. Reynolds, "Does nutritional intake differ between children with autism spectrum disorders and children with typical development?" Journal of Autism and Developmental Disorders, vol. 39, no. 2, pp. 212-222, 2009.

[4] M. H. Zimmer, L. C. Hart, P. Manning-Courtney, D. S. Murray, N. M. Bing, and S. Summer, "Food variety as a predictor of nutritional status among children with autism," Journal of Autism and Developmental Disorders, vol. 42, no. 4, pp. 549556, 2012.

[5] J. B. Adams, F. George, and T. Audhya, "Abnormally high plasma levels of vitamin B6 in children with autism not taking supplements compared to controls not taking supplements," Journal of Alternative and Complementary Medicine, vol. 12, no. 1, pp. 59-63, 2006.

[6] S. E. Levy, M. C. Souders, R. F. Ittenbach, E. Giarelli, A. E. Mulberg, and J. A. Pinto-Martin, "Relationship of dietary intake to gastrointestinal symptoms in children with autistic spectrum disorders," Biological Psychiatry, vol. 61, no. 4, pp. 492-497, 2007.

[7] C. R. Johnson, B. L. Handen, M. Mayer-Costa, and K. Sacco, "Eating habits and dietary status in young children with autism," Journal of Developmental and Physical Disabilities, vol. 20, no. 5, pp. 437-448, 2008. 
[8] G. L. Arnold, S. L. Hyman, R. A. Mooney, and R. S. Kirby, "Plasma amino acids profiles in children with autism: potential risk of nutritional deficiencies," Journal of Autism and Developmental Disorders, vol. 33, no. 4, pp. 449-454, 2003.

[9] C. Shimmura, S. Suda, K. J. Tsuchiya et al., "Alteration of plasma glutamate and glutamine levels in children with highfunctioning autism," PLoS ONE, vol. 6, no. 10, Article ID e25340, 2011.

[10] S. Aldred, K. M. Moore, M. Fitzgerald, and R. H. Waring, "Plasma amino acid levels in children with autism and their families," Journal of Autism and Developmental Disorders, vol. 33, no. 1, pp. 93-97, 2003.

[11] A. Ghanizadeh, "Could fever and neuroinflammation play a role in the neurobiology of autism? A subject worthy of more research," International Journal of Hyperthermia, vol. 27, no. 7, pp. 737-738, 2011.

[12] A. Ghanizadeh, "Targeting of glycine site on NMDA receptor as a possible new strategy for autism treatment," Neurochemical Research, vol. 36, no. 5, pp. 922-923, 2011.

[13] A. Ghanizadeh, "Methionine sulfoximine may improve inflammation in autism, a novel hypothesized treatment for autism," Archives of Medical Research, vol. 41, no. 8, pp. 651-652, 2010.

[14] A. Ghanizadeh and M. R. Namazi, "A possible research and clinical implication of association of homocysteine and glutamate levels in brain for management of aggression," International Journal of Developmental Neuroscience, vol. 28, no. 2, article 125, 2010.

[15] H. Moreno-Fuenmayor, L. Borjas, A. Arrieta, V. Valera, and L. Socorro-Candanoza, "Plasma excitatory amino acids in autism," Investigación Clínica, vol. 37, no. 2, pp. 113-128, 1996.

[16] W.-J. Tu, H. Chen, and J. He, "Application of LC-MS/MS analysis of plasma amino acids profiles in children with autism," Journal of Clinical Biochemistry and Nutrition, vol. 51, no. 3, pp. 248-249, 2012.

[17] R. Tirouvanziam, T. V. Obukhanych, J. Laval et al., "Distinct plasma profile of polar neutral amino acids, leucine, and glutamate in children with autism spectrum disorders," Journal of Autism and Developmental Disorders, vol. 42, no. 5, pp. 827836, 2011.

[18] G. Alfredsson, F.-A. Wiesel, and A. Tylec, "Relationships between glutamate and monoamine metabolites in cerebrospinal fluid and serum in healthy volunteers," Biological Psychiatry, vol. 23, no. 7, pp. 689-697, 1988.

[19] A. Shinohe, K. Hashimoto, K. Nakamura et al., "Increased serum levels of glutamate in adult patients with autism," Progress in Neuro-Psychopharmacology \& Biological Psychiatry, vol. 30, no. 8, pp. 1472-1477, 2006.

[20] L. A. Page, E. Daly, N. Schmitz et al., "In vivo ${ }^{1}$ H-magnetic resonance spectroscopy study of amygdala-hippocampal and parietal regions in autism," American Journal of Psychiatry, vol. 163, no. 12, pp. 2189-2192, 2006.

[21] T. L. Perry, S. Hansen, and R. G. Christie, "Amino compounds and organic acids in CSF, plasma, and urine of autistic children," Biological Psychiatry, vol. 13, no. 5, pp. 575-586, 1978.

[22] H. Moreno, L. Borjas, A. Arrieta et al., "Clinical heterogeneity of the autistic syndrome: a study of 60 families," Investigacion Clinica, vol. 33, no. 1, pp. 13-31, 1992.

[23] A. Ali, M. I. Waly, Y. M. Al-Farsi, M. M. Essa, M. M. AlSharbati, and R. C. Deth, "Hyperhomocysteinemia among Omani autistic children: a case-control study," Acta Biochimica Polonica, vol. 58, no. 4, pp. 547-551, 2011.
[24] S. P. Paşca, B. Nemeş, L. Vlase et al., "High levels of homocysteine and low serum paraoxonase 1 arylesterase activity in children with autism," Life Sciences, vol. 78, no. 19, pp. 22442248, 2006.

[25] S. J. James, P. Cutler, S. Melnyk et al., "Metabolic biomarkers of increased oxidative stress and impaired methylation capacity in children with autism," The American Journal of Clinical Nutrition, vol. 80, no. 6, pp. 1611-1617, 2004.

[26] J. Kałuzna-Czaplińska, M. Michalska, and J. Rynkowski, "Homocysteine level in urine of autistic and healthy children," Acta Biochimica Polonica, vol. 58, no. 1, pp. 31-34, 2011.

[27] L. H. Rolf, F. Y. Haarmann, K.-H. Grotemeyer, and H. Kehrer, "Serotonin and amino acid content in platelets of autistic children," Acta Psychiatrica Scandinavica, vol. 87, no. 5, pp. 312316, 1993

[28] K. D. MacDermot, E. Bonora, N. Sykes et al., "Identification of FOXP2 truncation as a novel cause of developmental speech and language deficits," American Journal of Human Genetics, vol. 76, no. 6, pp. 1074-1080, 2005.

[29] A. Ghanizadeh, S. Akhondzadeh, M. Hormozi, A. Makarem, M. Abotorabi-Zarchi, and A. Firoozabadi, "Glutathione-related factors and oxidative stress in autism, a review," Current Medicinal Chemistry, vol. 19, no. 23, pp. 4000-4005, 2012.

[30] C. Evans, R. H. Dunstan, T. Rothkirch et al., "Altered amino acid excretion in children with autism," Nutritional Neuroscience, vol. 11, no. 1, pp. 9-17, 2008.

[31] A. L. Sheldon and M. B. Robinson, "The role of glutamate transporters in neurodegenerative diseases and potential opportunities for intervention," Neurochemistry International, vol. 51, no. 6-7, pp. 333-355, 2007.

[32] S. H. Fatemi, "The hyperglutamatergic hypothesis of autism," Progress in Neuro-Psychopharmacology and Biological Psychiatry, vol. 32, no. 3, article 911, 2008.

[33] R. L. Blaylock and A. Strunecka, "Immune-glutamatergic dysfunction as a central mechanism of the autism spectrum disorders," Current Medicinal Chemistry, vol. 16, no. 2, pp. 157$170,2009$.

[34] S. H. Fatemi, A. R. Halt, J. M. Stary, R. Kanodia, S. C. Schulz, and G. R. Realmuto, "Glutamic acid decarboxylase 65 and $67 \mathrm{kDa}$ proteins are reduced in autistic parietal and cerebellar cortices," Biological Psychiatry, vol. 52, no. 8, pp. 805-810, 2002.

[35] E. Schwarz, P. C. Guest, H. Rahmoune et al., "Sex-specific serum biomarker patterns in adults with Asperger's syndrome," Molecular Psychiatry, vol. 16, no. 12, pp. 1213-1220, 2011.

[36] A. Ghanizadeh, M. R. Mohammadi, T. Sadeghiyeh, A. A. Shooshtari, and S. Akhondzadeh, "Symptoms of children with autism spectrum disorder, a clinical sample," Iranian Journal of Psychiatry, vol. 4, no. 4, pp. 165-169, 2009.

[37] M.-L. Mattila, T. Hurtig, H. Haapsamo et al., "Comorbid psychiatric disorders associated with asperger syndrome/highfunctioning autism: a community- and clinic-based study," Journal of Autism and Developmental Disorders, vol. 40, no. 9, pp. 1080-1093, 2010.

[38] A. Ghanizadeh, "Co-morbidity and factor analysis on attention deficit hyperactivity disorder and autism spectrum disorder DSM-IV-derived items," Journal of Research in Medical Sciences, vol. 17, no. 4, pp. 368-372, 2012.

[39] L. Tidmarsh and F. R. Volkmar, "Diagnosis and epidemiology of autism spectrum disorders," Canadian Journal of Psychiatry, vol. 48 , no. 8 , pp. 517-525, 2003. 
[40] M. O. Mazurek, R. A. Vasa, L. G. Kalb et al., "Anxiety, sensory over-responsivity, and gastrointestinal problems in children with autism spectrum disorders," Journal of Abnormal Child Psychology, vol. 41, no. 1, pp. 165-176, 2013.

[41] P. Louis, "Does the human gut microbiota contribute to the etiology of autism spectrum disorders?" Digestive Diseases and Sciences, vol. 57, no. 8, pp. 1987-1989, 2012.

[42] J. Bienenstock and S. Collins, "99th Dahlem conference on infection, inflammation and chronic inflammatory disorders: psycho-neuroimmunology and the intestinal microbiota: clinical observations and basic mechanisms," Clinical and Experimental Immunology, vol. 160, no. 1, pp. 85-91, 2010.

[43] T. A. Clayton, "Metabolic differences underlying two distinct rat urinary phenotypes, a suggested role for gut microbial metabolism of phenylalanine and a possible connection to autism," FEBS Letters, vol. 586, no. 7, pp. 956-961, 2012. 


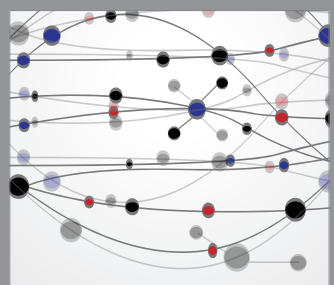

The Scientific World Journal
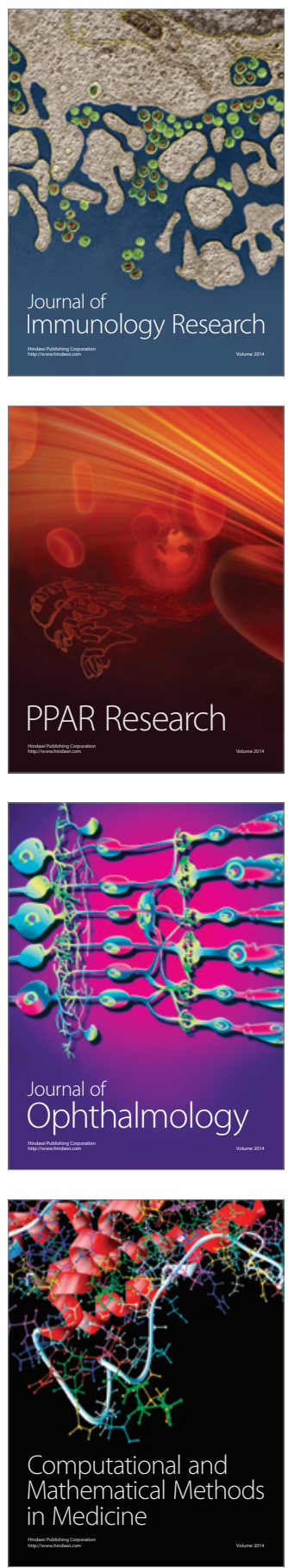

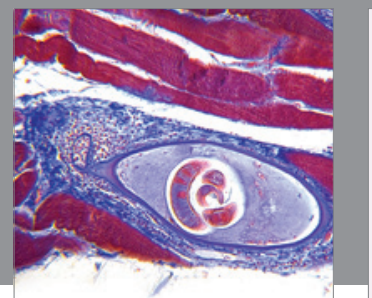

Gastroenterology

Research and Practice


\section{Hindawi}

Submit your manuscripts at

http://www.hindawi.com

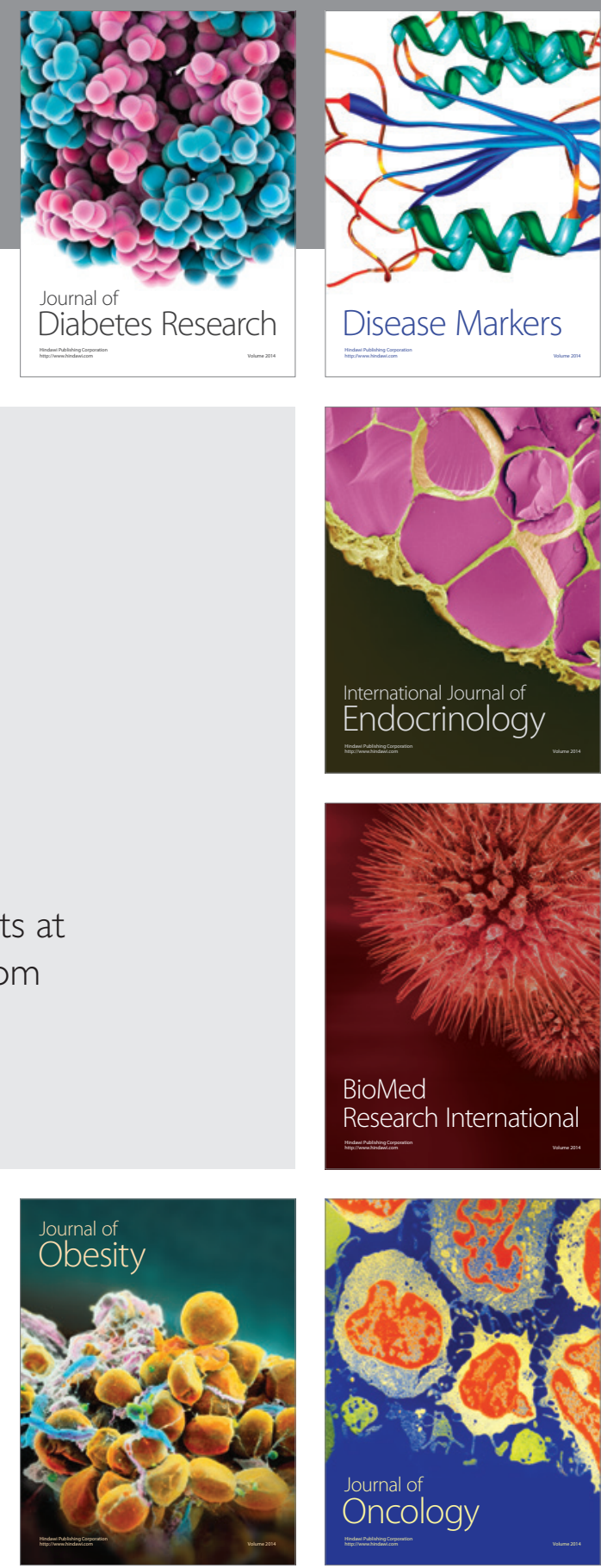

Disease Markers
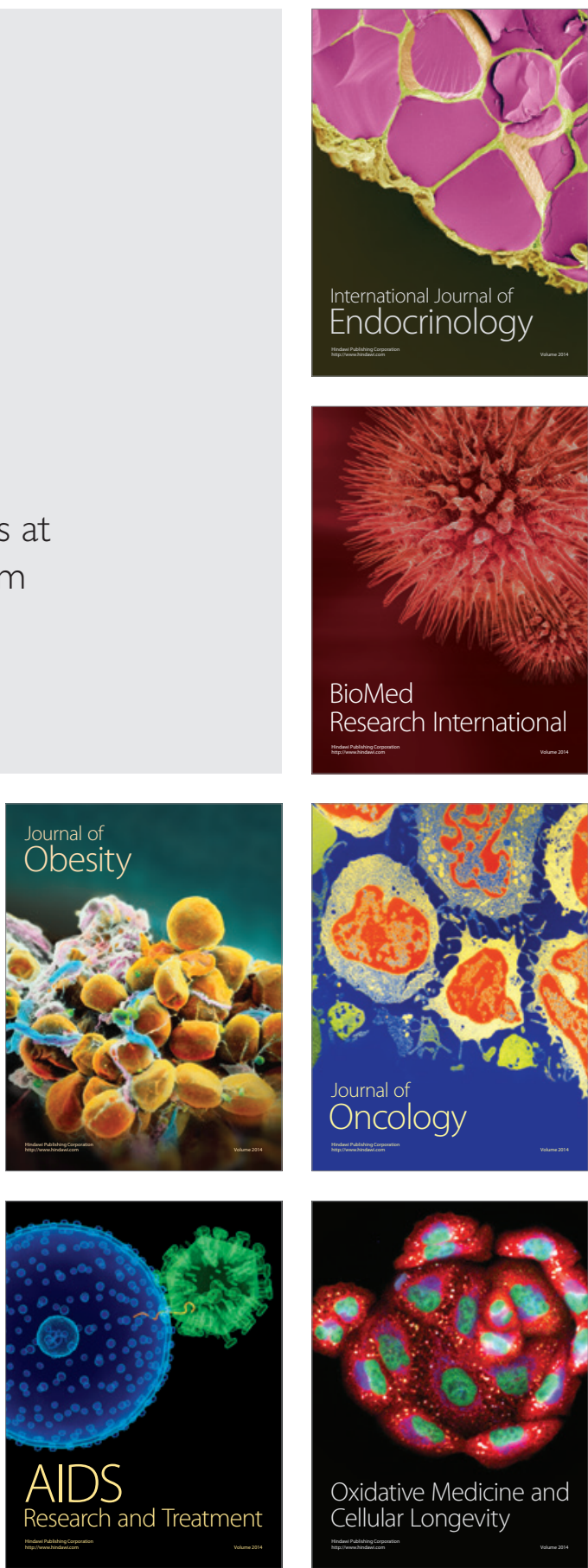